Hydrol. Earth Syst. Sci., 17, 1297-1307, 2013

www.hydrol-earth-syst-sci.net/17/1297/2013/

doi:10.5194/hess-17-1297-2013

(c) Author(s) 2013. CC Attribution 3.0 License.

\title{
Assessment of shallow subsurface characterisation with non-invasive geophysical methods at the intermediate hill-slope scale
}

\author{
S. Popp, D. Altdorff, and P. Dietrich \\ UFZ, Helmholtz Centre for Environmental Research, Department Monitoring and Exploration Technologies, \\ Leipzig, Germany
}

Correspondence to: S. Popp (steffen.popp@ufz.de) and P. Dietrich (peter.dietrich@ufz.de)

Received: 26 January 2012 - Published in Hydrol. Earth Syst. Sci. Discuss.: 24 February 2012

Revised: 2 February 2013 - Accepted: 9 March 2013 - Published: 2 April 2013

\begin{abstract}
Hill-slopes of several hectares in size represent a difficult scale for subsurface characterisation, as these landscape units are well beyond the scope of traditional pointscale techniques. By means of electromagnetic induction (EMI) and gamma-ray spectroscopy, spatially distributed soil proxy data were collected from a heterogeneous hill-slope site. Results of EMI mapping using the EM38DD showed that soil electrical conductivity (ECa) is highly variable at both temporal and spatial scales. Calibration of the integral ECa signal to a specific target like soil moisture is hampered by the ambiguous response of EMI to the clay-rich hill-slope underground. Gamma-ray results were obtained during a single survey, along with EMI measurements and selected soil sampling. In contrast to ECa, a noticeable correlation between Total Count and K emission data and soil-water content seemed to be present. Relevant proxy variables from both methods were used for $k$ means clustering in order to distinguish between hill-slope areas with different soil conditions. As a result, we obtained a suitable partition of hillslope that was comparable with a previously obtained zonation model based on ecological factors.
\end{abstract}

\section{Introduction}

Exploration of near-surface ground on hill-slopes still poses a significant challenge in hydrological or natural-hazard sciences due to subsurface heterogeneity at intermediate landscape scales (commonly less than one square kilometre). Point measurements, e.g., in situ soil-moisture determination by specific probes or sediment sampling for laboratory analyses provide quantitative data, however, only from a very limited area or volume of the subsurface. As point measures are relatively costly and time consuming, sampling is often limited to a few selected points. Scaling up point data in order to infer information for the entire hill-slope area is problematic, with respect to the heterogeneous underground.

Geophysical methods provide the possibility of gathering spatially distributed data and are, thus, nowadays being increasingly applied to landscape characterisation (Schrott and Sass, 2008; Van Damm, 2012). Besides structural prospecting in hill-slope and landslide studies in addition to geological investigations (e.g., Chambers et al., 2011; Sass et al., 2008), geophysical techniques are widely-used for the spatial mapping of physical variables, e.g., electrical conductivity (EC). EC is a key parameter for the description of near-surface ground due to its close relationship to soil and hydrological properties (Carroll and Oliver, 2005; Corwin and Lesch, 2003; Ewing and Hunt, 2006; Brevik et al., 2006). Ground-based electromagnetic induction (EMI) methods have proven an efficient technique for rapid and area-wide mapping of soil EC. EMI measures a depthweighted average of the soil electrical conductivity to a specific depth, the so-called apparent electrical conductivity ( $\mathrm{ECa}$ in milli Siemens per meter, $\mathrm{mS} \mathrm{m}^{-1}$ ). Thereby, $\mathrm{ECa}$ is a sum parameter and predominately influenced by the volumetric water content, salinity, the types and amount of clay minerals, porosity, and soil temperature (McNeil, 1980a). Due to these relationships, ECa is used in many studies as proxy value for estimating or predicting soil properties such as salinity (e.g., Kinal et al., 2006), clay layers (e.g., Cockx et al., 2007), soil texture (e.g., Domsch and Giebel, 2004), and very often soil moisture (e.g., Sheets and Hendrickx, 1995; Reedy and Scanlon, 2003; Martinez et al., 2010). For 
prediction, the relationship between ECa and the target quantity has to be analysed, which is commonly realised by point measures. EMI-based soil-moisture determination, for example, was successfully achieved at flat, relatively homogeneous and rather small sites with a significant effort for numerous point measures (see cited studies).

Generally, one has to face uncertainties due to different sample volumes of EMI method with regard to the target in the subsurface, which is commonly a soil sample from a specific depth. These uncertainties become more pronounced with increasing heterogeneity and complexity of the study site. Callegary et al. (2012), therefore, suggest a detailed analysis of depth sensitivity of EMI in order to avoid overestimations of ECa values at a certain point of measurement that is caused by spatially variable sensitivities within the sample volume of the EMI sensor. While this study provides theoretical consideration of the problem based on numerical simulations, experimental results from hill slopes show the difficulties of EMI application in an environment, where spatial heterogeneity exceeds those of the senor's sample volume. For example, Tromp-van Meerveld and McDonnell (2009) gave a nice example of the effort and remaining uncertainties for predicting soil water contents at a rather small hill slope of less than $0.001 \mathrm{~km}^{2}$. The authors achieved a reliable correlation for predicting soil moisture with $\mathrm{ECa}$ values, however, only by using individual relationships determined at each of the sixty-four measuring points. The use of one (master) relationship for the calculation of water contents resulted in a smoothed soil-moisture pattern that did not represent the observed soil-moisture pattern very well. At larger hill-slope scales, Robinson et al. (2012) used a qualitative time-lapse approach for revealing relative changes in soil moisture that avoided the problem of calibrating ECa values to individual soil-moisture samples. On the other hand, if the subsurface target is relatively large compared to the sample volume, e.g., soil depth (depth to bedrock), EMI provided suitable results in soil-quality investigations at a large agricultural site of nearly $0.2 \mathrm{~km}^{2}$ (Zhu et al., 2010a). Generally, the effort required for ground truthing and reliable calibration of EMI results to a relatively small target (soil samples) increases significantly in proportion to the size and complexity of the study site for both theoretical and experimental considerations. Thus, if adequate soil sampling is not possible or not suitable due to the site conditions or time and cost constraints, other approaches for extracting subsurface information should be adopted.

In the present study, we have focused on the primary characterisation of a large and very heterogeneous hill slope by statistical analysis of geophysical results. For investigation of the hill-slope area, we included a second geophysical method for investigation because of specific site conditions. Under the proposition of a rapid and non-invasive technique we had chosen gamma spectroscopy, because the electrically conductive clay-rich subsurface hampered the use of e.g., ground penetrating radar (GPR). Gamma-ray spectroscopy measures gamma-ray radiation emitted from the natural decay of radioactive elements that are present in rocks and soils (e.g., Minty, 1997; Dickson and Scott, 1997; Wilford et al., 1997). Both the concentration and the ratio of specific radioactive elements can give information on soil properties such as surface texture (e.g., Taylor et al., 2002), clay content (e.g., Pracilio et al., 2006), or soil-moisture patterns (e.g., Carroll, 1981; Grasty, 1997).

The goal of this study is the reasonable exploration and characterisation of the hill-slope subsurface based on mapping of soil proxy values with geophysics. Thereby, we try to minimise the need for invasive measures because soil sampling and soil testing are commonly critical points due to time and cost constraints. The number of soil samples is, therefore, restricted to a manageable quantity of less than 20 samples, which are used for a basic evaluation of both methods under site-specific condition. Following the statistical approach, we target at a spatially meaningful partitioning of the heterogeneous subsurface as basis for further detailed investigations, and compare the geophysical-based results with a previously obtained hill-slope zonation from hydrological and soil-survey studies.

\section{Material and methods}

\subsection{Study site}

The study area Heumöser (Fig. 1) is located near the Rhine River valley in the western Vorarlberg Alps, Austria, around $10 \mathrm{~km}$ south of city of Dornbirn and $0.5 \mathrm{~km}$ south of the village of Ebnit $\left(47^{\circ} 21^{\prime} 0.0^{\prime \prime} \mathrm{N}, 9^{\circ} 44^{\prime} 46.6^{\prime \prime} \mathrm{E}\right)$. The Heumöser belongs to the head of a steep mountainous catchment and covers $0.95 \mathrm{~km}^{2}$ with an extension of 1800 and $500 \mathrm{~m}$ in eastwest and north-south directions, respectively. The bedrocks that underlie and surround the Heumöser slope are sedimentary marlstones from the Upper Cretaceous, belonging to the Alpine Helvetic zone (Lindenmaier et al., 2005). Unweathered marlstones are a mixture of calcite, quartz and clay minerals. The cover sediments, which reach a thickness of up to $40 \mathrm{~m}$, are described as loamy scree and glacial till with variable proportions of calcite (up to $40 \%$ ), quartz (25-40\%), and clay (up to $30 \%$ ) (Schneider, 1999). The water content of these sediments ranges from 20 to $30 \%$. In soil profiles, water content and proportions of clay can vary and, in particular, the water content can be significantly increased.

The Heumöser is a slow moving landslide with surface movement rates of 0.01 to $0.25 \mathrm{~m} \mathrm{yr}^{-1}$ (Depenthal and Schmidt, 2003). The mobility is predominantly controlled by hydrological processes such as pore-water pressure fluctuations and the variable weight of soil due to variable water contents (Lindenmaier et al., 2005; Wienhöfer et al., 2011). Inclinometer measurements in boreholes (Fig. 1) identified subsurface deformation along a shear zone between 


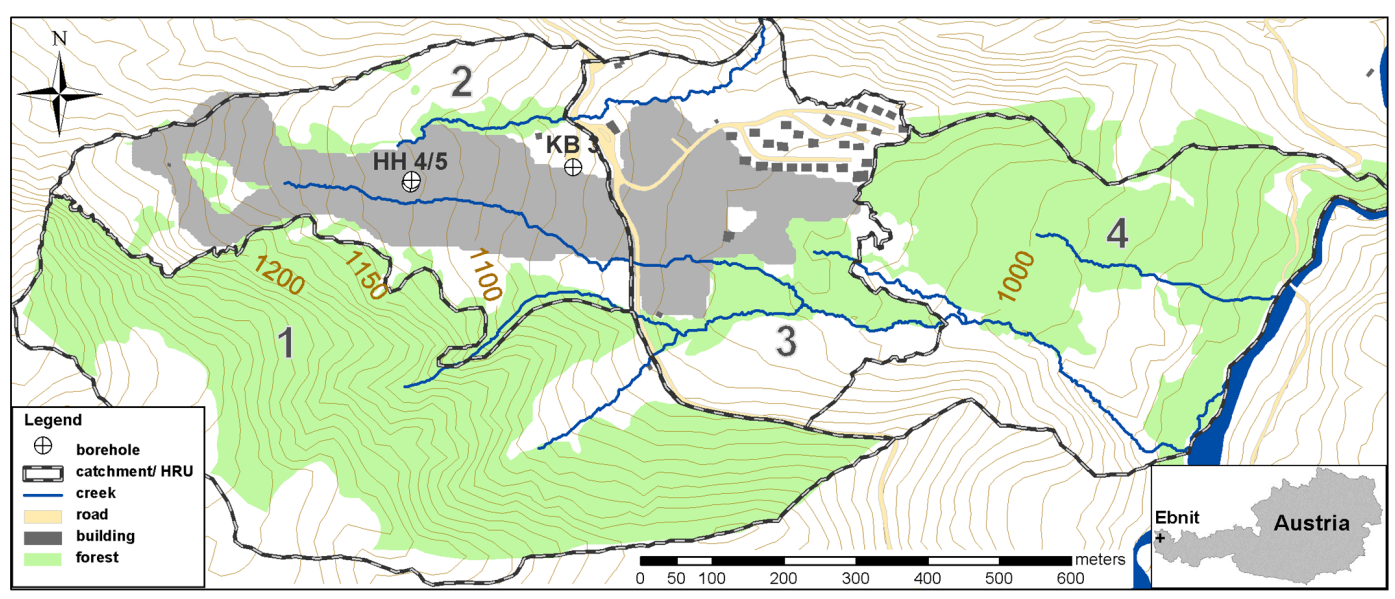

Fig. 1. Topography of the Heumöser catchment near Ebnit (Vorarlberg, Austria). The grey-shaded region indicate the open meadow area, on which geophysical mapping was focused. Numbers 1 to 4 denote the major hydrologic units (HRU). HH 4/5 and KB3 indicate the location of boreholes used for inclinometer measurements that specify the surface movement of the slope (see text).

7.5 and $8.5 \mathrm{~m}$ depths in KB3 (Schneider, 1999), and between 10.5 and $12.0 \mathrm{~m}$ depths in HH4 (Wienhöfer et al., 2011).

The geophysical surveys for shallow subsurface exploration focus on the accessible meadow areas in the middle and north-western parts of the Heumöser (Fig. 1) between 1039 and $1233 \mathrm{~m}$ altitude. This area covers approximately 13 ha with maximum extension of 1030 and $300 \mathrm{~m}$ in eastwest and north-south directions, respectively. The topography is highly variable, with relatively steep and hummocky terrain in the west with an average slope angle of $19.5^{\circ}$, and a rather plane surface in the east. The Heumöser is subdivided into four so-called hydrotopes or hydrologic response units (HRU), according to long-term average soil moisture patterns found in detailed botanic and hydropedologic mapping (Lindenmaier et al., 2005; Wienhöfer et al., 2011). The investigated slope area belongs to HRU 2 and 3, which are generally characterised by very moist to very wet topsoil conditions in plane areas, and dryer conditions in bulging areas (Fig. 1). In combination with the significant proportion of clay, the soil surface is electrically high conductive, which hinders the application of GPR and time domain reflectometry (TDR). Outcrops of bedrocks additionally prevent invasive measures in some places of the hill slope.

\subsection{Electromagnetic measurements}

We conducted two electromagnetic mapping surveys at the beginning of May and in the middle of June 2011. The first field survey aimed at a general and rapid characterisation of hill-slope subsurface by "on-the-go" ECa measurements, with an average line spacing of $15 \mathrm{~m}$ (Fig. 2a). In June 2011, ECa proximal sensing was conducted as point measurements in conjunction with gamma-ray spectroscopy at 327 locations. Additional soil samples were taken at 18 locations. The May survey was performed under highly water-saturated soil conditions, shortly after all snow had fully melted. The second field measurement in June was assumed to be carried out under changed subsurface conditions (in terms of less water saturated). In all surveys, spatial reference of sampling points was determined by an external D-GPS system (Leica 1200) connected to the EMI recording unit.

We used the EM38DD electromagnetic induction sensor (Geonics Ltd., ON, Canada) for mapping soil electrical conductivity. The sensor operates in the frequency domain at fixed coil spacing of $1 \mathrm{~m}$. An alternating current at a specific frequency in the transmitter coil induces a primary electromagnetic field that propagates through the subsurface and generates a secondary magnetic field. The receiver coil detects the primary and secondary magnetic fields at the surface. The ratio of these two readings gives the depthweighted apparent electrical conductivity ( $\mathrm{ECa}$ in $\mathrm{mS} \mathrm{m}^{-1}$ ). The EM38DD consist of two EM38 units fixed perpendicularly to each other with operating frequencies of 14.6 and $17.0 \mathrm{kHz}$, respectively. This construction results in two simultaneous conductivity readings with different depth response profiles. The sensor in vertical orientation (EC_v) receives its major influence from the shallow subsoil with a common exploration depth of up to $1.5 \mathrm{~m}$ (McNeil, 1980b). The horizontally orientated sensor $(\mathrm{EC} h$ h) is most sensitive to the uppermost topsoil and reaches depths of $0.75 \mathrm{~m}$. Before surveying, the EM38DD sensor was calibrated at the same point on the site according to the user manual at the beginning of each field site measurement day. Additionally, we recorded a reference profile repeatedly both before and in between the measurements in order to check data quality and serviceability of the instrument.

To avoid interferences to EMI response whilst surveying, an appropriate distance from the metallic masts of the ski lift has to be maintained. Further outliers in the ECa dataset which occurred as a result of non-visible EMI interferences 

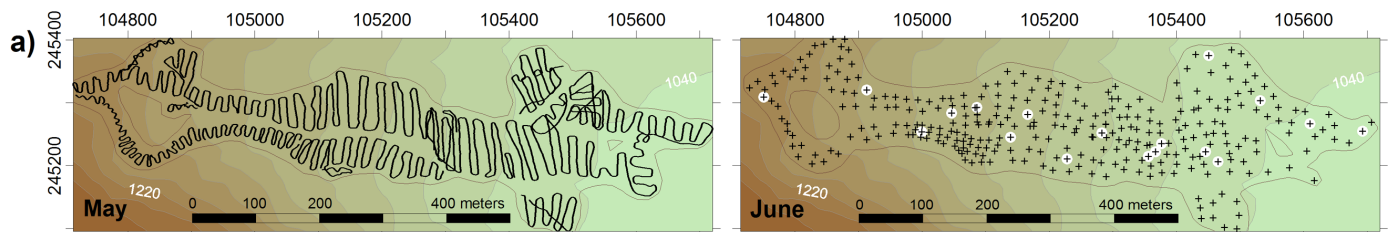

b)
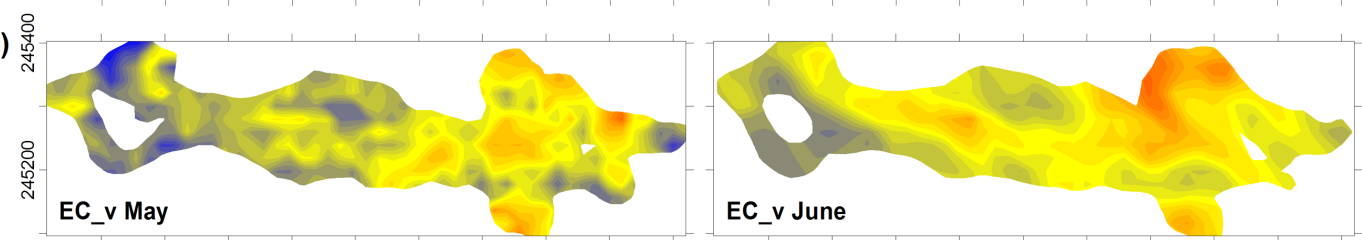

c)
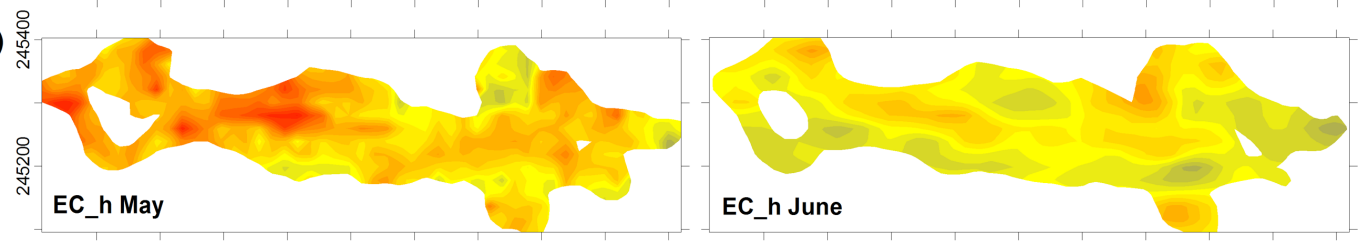

d)

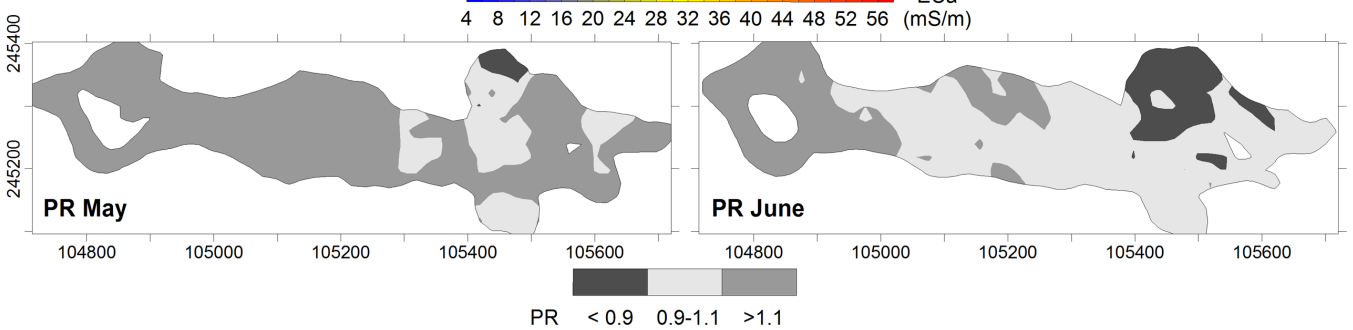

Fig. 2. EMI measurements from May (left column) and June (right column) with different survey designs and location of reading points (a). White dots in the map on the right show soil sampling locations. The detail views show maps obtained by block ordinary kriging of ECa $\left(\mathrm{mS} \mathrm{m}^{-1}\right)$ using (b) the vertical (EC_v) and (c) the horizontal dipole orientation (EC_h), as well as (d) the profile ratio (PR). Coordinates on $\mathrm{x}$ - and $\mathrm{y}$-axis are in metric BMN M28 Austrian coordinate system.

were removed, while data analysis was performed by applying a filter that only allows for data within the triple of the root-mean-square deviation to be considered. Since soil electrical conductivity can vary due to changes in soil temperature, we standardised the field apparent conductivity values to an equivalent conductivity at a reference temperature $\left(25^{\circ} \mathrm{C}\right)$ using soil temperatures measured at two locations on the slope and a conversion function given by Sheets and Hendrickx (1995) and Reedy and Scanlon (2003):

$\mathrm{EC}_{25}=\mathrm{EC}_{\mathrm{a}}\left(0.4779+1.3801 e^{\left(\frac{-T}{25.654}\right)}\right)$

where $\mathrm{EC}_{25}$ is the temperature corrected apparent conductivity, $\mathrm{EC}_{\mathrm{a}}$ is the measured apparent conductivity $\left(\mathrm{mS} \mathrm{m}^{-1}\right)$, and $T$ is the soil temperature $\left({ }^{\circ} \mathrm{C}\right)$. Soil temperature measured at $10-\mathrm{cm}$ soil depth was in average 8.5 and $15^{\circ} \mathrm{C}$ in May and June, respectively. When discussing apparent conductivity in the following sections, we always refer to the temperature corrected values. Maps of shallow subsurface apparent conductivity were obtained by variogram analysis and ordinary kriging interpolation, using a $20 \mathrm{~m}$ grid.

\subsection{Gamma ray spectroscopy}

For proximal gamma-ray sensing, we used the portable $E x$ ploranium GR256 gamma-ray spectrometer with a $0.35 \mathrm{~L}$ thallium activated NaI crystal detector (Exploranium, Ontario, Canada). The gamma sensor detects the gamma radiation of variable energies that is emitted by the natural decay of radioactive elements present in rocks and soils. Thereby, about $90 \%$ of the gamma radiation measured at the surface emanates from the upper $30 \mathrm{~cm}$, and about $50 \%$ comes from the top $10 \mathrm{~cm}$ (e.g., Cook et al., 1996).

At the Heumöser, gamma-ray measurements were taken at 327 points by placing the detector on the ground surface. A single measurement took 60 seconds to complete, which was evaluated by test measurements to be an adequate time interval, with regards to signal stability and the number of measuring points. According to the default settings of the spectrometer, gamma radiation was measured in four energy windows, so-called "regions of interest" (ROI), with specific energy ranges that allow for the detection of total number of decays (Total Count), as well as of potassium- $40(\mathrm{~K})$, uranium238 (U) and thorium-232 (Th) (cf. Viscarra Rossel et al., 2007). Individual gamma data and local variogram were used 
Table 1. Descriptive statistics of EMI measurements (in $\mathrm{mS} \mathrm{m}^{-1}$ ) in horizontal (EC_h) and vertical (EC_v) dipole configuration and gammaray spectroscopy (in counts per $60 \mathrm{~s}$ ). SD: standard deviation, CV: coefficient of variation [(SD/Mean) $\times 100]$.

\begin{tabular}{lrrrrllll}
\hline & $\begin{array}{r}\text { EC_h } \\
\text { May }\end{array}$ & $\begin{array}{r}\text { EC_v } \\
\text { May }\end{array}$ & $\begin{array}{r}\text { EC_h } \\
\text { June }\end{array}$ & $\begin{array}{r}\text { EC_v } \\
\text { June }\end{array}$ & $\begin{array}{l}\text { Gamma } \\
\text { K }\end{array}$ & $\begin{array}{l}\text { Gamma } \\
\text { U }\end{array}$ & $\begin{array}{l}\text { Gamma } \\
\text { Th }\end{array}$ & $\begin{array}{l}\text { Total } \\
\text { count }\end{array}$ \\
\hline Mean & 37.1 & 26.7 & 31.3 & 30.4 & 226 & 60 & 36 & 1230 \\
Min & 17.0 & 1.0 & 11.8 & 10.4 & 44 & 13 & 11 & 393 \\
Max & 57.3 & 52.2 & 56.5 & 60.1 & 583 & 125 & 83 & 2537 \\
SD & 6.4 & 8.0 & 7.0 & 8.2 & 85 & 17 & 12 & 346 \\
CV [\%] & 17.3 & 30.0 & 22.4 & 27.0 & 37.6 & 28.3 & 33.3 & 28.1 \\
\hline
\end{tabular}

for kriging interpolation on a $20 \mathrm{~m}$ grid analogue to the $\mathrm{ECa}$ values.

\section{Results and discussion}

\subsection{Apparent electromagnetic conductivity measurements}

Soil electrical conductivity is highly variable on the hillslope. The overall range of $\mathrm{ECa}$ is between 1 and $60 \mathrm{mS} \mathrm{m}^{-1}$, with coefficients of variation (CV) in the range of 17 to $30 \%$ for individual EC_h and EC_v measurements (Table 1). Differences data ranges and $\mathrm{CV}$ between $\mathrm{EC} \mathrm{h}_{\mathrm{h}}$ and EC_v during one survey originate from different sample volumes or exploration depths of the respective dipole orientations. Results of kriging interpolation reveal defined spatial pattern of $\mathrm{ECa}$ (Fig. $2 \mathrm{~b}$ and c) that can be explained in a site-specific context.

In May, soil apparent conductivity shows a significant vertical gradient from a very conductive top soil (EC_h response) towards less conductive deeper layers (EC_v response) in most parts of the hill-slope. While zones of low EC_V readings $\left(<20 \mathrm{mS} \mathrm{m}^{-1}\right)$ in the steeper eastern hillslope area can be partly attributed to near-surface bed rock ( $<1 \mathrm{~m}$ deep), the high EC_h readings are very likely linked to clay-rich soils and/ or high water contents of the top soil after snowmelt. In June, vertical graduation of ECa was less pronounced due to decreased conductivity of the top soil. Both the EC_h and EC_v readings can be used for the calculation of a profile ratio (PR), as an indication for the heterogeneity of the soil column, defined as: $\mathrm{PR}=\mathrm{EC} \mathrm{h} / \mathrm{EC}_{-} \mathrm{v}$ (Corwin et al., 2003; Cockx et al., 2007). A PR close to 1 points to a uniform profile of soil electrical conditions. A PR $<1$ indicates a more conductive subsoil relative to the topsoil, and a $\mathrm{PR}>1$ indicates a conductive topsoil and decreasing conductivity with depth. Figure $2 \mathrm{~d}$ shows the areas of the hill-slope with different vertical graduations. In May, the majority of the hill-slope subsurface is dominated by conductive topsoil conditions $(\mathrm{PR} \gg 1)$. The situation had changed in June, where relatively uniform soil conditions $(\mathrm{PR} \sim 1)$ with intermediate electrical conductivities prevailed over nearly half of the hill-slope area.

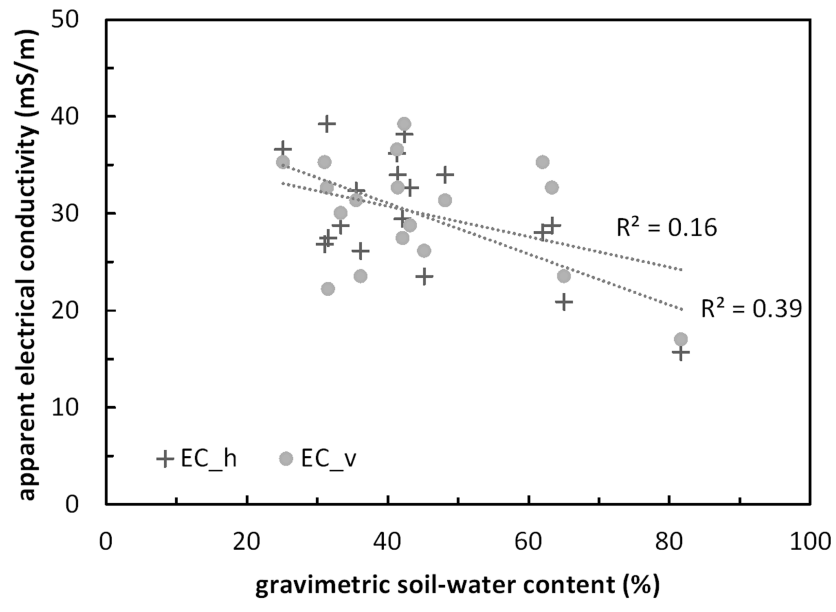

Fig. 3. Scatterplot of gravimetric soil-water content and ECa data, separated into EC_h and EC_V according to the respective sensor orientation in June survey.

For a rapid assessment of ECa response, we analysed the prominent relation between soil-water content and electrical conductivity by determining the gravimetric soil-water content in laboratory. Soil samples were collected at 18 locations from depths between 10 and $40 \mathrm{~cm}$, along with ECa point measurements in June. The location of soil samples is shown in Fig. 2a. Gravimetric soil-water contents range from 25 to $82 \%$ relative to the dry weight of the soil sample. Highest values of 62 to $82 \%$ were determined at four organic-rich soil samples located in the flat eastern part of the hill-slope, while most of the samples show water contents in the range of 25 to $48 \%$. As shown in Fig. 3, there exists no statistically significant correlation between soil-water content and ECa at the time of sampling, neither with EC_h nor with EC_v. The suggested, but insignificant, correlation of EC $\mathrm{h}$ is obviously caused by the exceptionally high water contents of few organic-rich soil-samples. Evidently, ECa at the study site is not to solely dependent upon water saturation, but also on soil structure and mineral content. At the Heumöser, soils are described as gley and stagno gley soils, or silty clay to silty loams according to the US soil taxonomy (Lindenmaier et al., 2005). Relatively high proportions of clayey and silty 


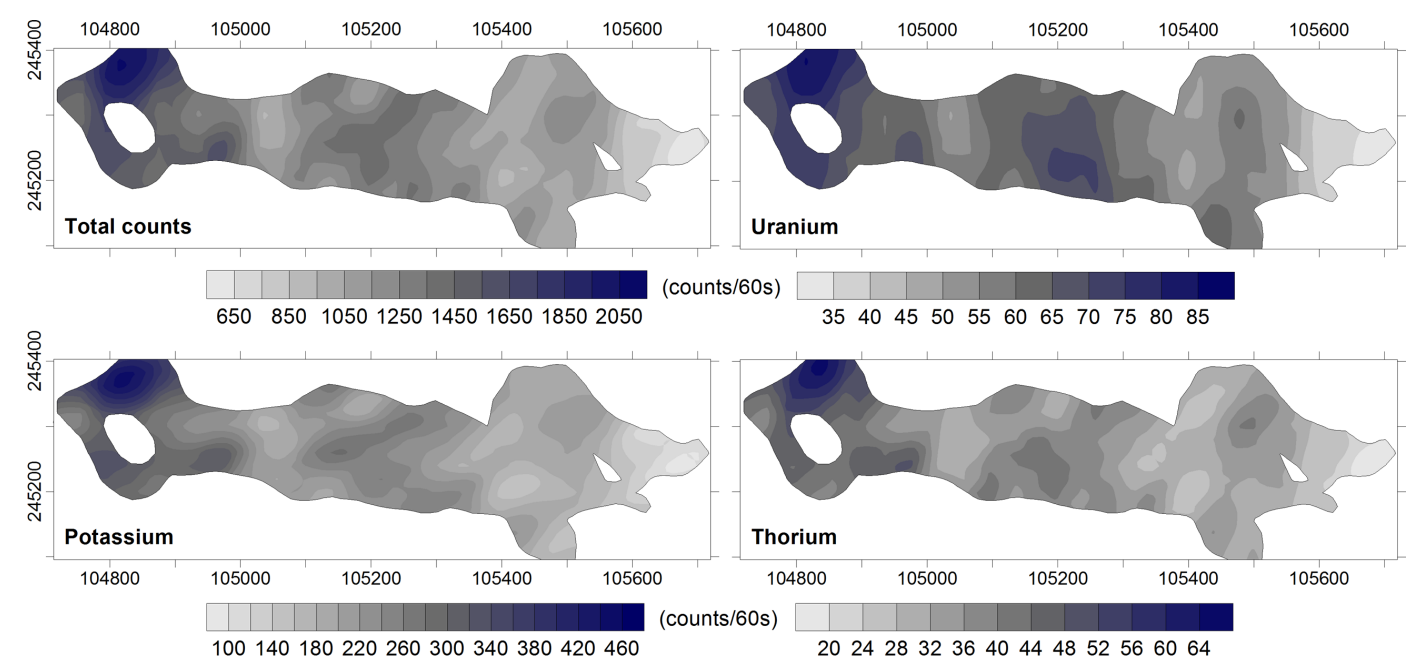

Fig. 4. Maps of interpolated gamma radiation (in counts per $60 \mathrm{~s}$ ) using individual data of Total Count (top left panel), potassium or K (bottom left panel) uranium or U (top right panel), and thorium or Th (bottom right panel). Note the different scales of data ranges. Coordinates on $\mathrm{x}$ - and $\mathrm{y}$-axis are in metric BMN M28 Austrian coordinate system.

material, which were also evident in the recovered soil samples, are supposed to contribute significantly to the integral signal of soil electrical conductivity. This issue can obviously result in relatively low ECa readings for organic soils even though the soil-water content is high, and vice versa, in relatively high ECa values for clayey soils with lower gravimetric soil-water content. The distinction between temporally variable soil moisture and the geological background based on a single EMI mapping survey is not possible at the site.

However, given that the type and amount of clay minerals, soil structure, and ionization of the soil moisture do not change over the considered period of time, ECa variations in repeated measurements are presumably linked to relative changes in soil moisture (Robinson et al., 2009, 2012; Zhu et al., 2010b). On the site, temporal ECa variability is more pronounced in the EC_h (topsoil) than in the EC_v (subsoil) response. In May, higher apparent conductivities of ECh over wide areas in the steeper west could point to relative higher soil-moisture contents compared to the topsoil conditions in June. On the other hand, EC_v results show similar spatial pattern in both May and June surveys with low apparent conductivity in the steeper west and higher apparent conductivities in the eastern part, which could be explained by the stagnic properties of the silty and clayey subsoil. This interpretation is reinforced by findings from a local TDR profile measured at the hill-slope, where almost no soil-moisture variation occurred in the deeper subsoil $(80 \mathrm{~cm}$ depth), while data at a $20 \mathrm{~cm}$ depth shows around $10 \%$ of seasonal variation in soil moisture (Lindenmaier et al., 2005).

\subsection{Gamma-ray survey}

Gamma-ray emission is relatively low at the hill-slope with maximum values of 583, 83 and 125 counts per 60 s for K,
Th and $U$ (Table 1). Total Count, which is the sum signal of all radioactive emissions, reaches maximum 2537 counts per $60 \mathrm{~s}$. Despite the low emission rates and relatively minor data ranges, the variability of gamma-ray flux data is high and more pronounced at smaller spatial scales compared to EMI. For example, gamma-ray flux between two neighbouring sampling points can differ significantly from each other due to the small support volume of the gamma-ray method and changing subsurface microstructures. As a result, coefficients of variation are in the range of 28 and $38 \%$ (Table 1). However, regardless of the pronounced small-scale variability, gamma-ray emission data show definite spatial pattern at the hill-slope scale similar to those of ECa.

As shown by the maps obtained from kriging interpolation, highest emission values are concentrated in the northwestern part of the slope (Fig. 4). According to the situation in field, these high radioactive emission values are very likely caused by allochthonous material from a backfill on the ski trail. The majority of emission values (around $90 \%$ of data) for Total Count and $\mathrm{K}$ is below 1700 and 400 counts per $60 \mathrm{~s}$, respectively, indicating shallow subsurface concentrations lower than $1 \mathrm{ppm}$ (U equivalent) for Total Count and lower than $0.5 \%$ for K. When we consider the mineral composition of loamy scree sediments of the subsoil, consisting among others of K-bearing minerals illite and muscovite (up to $10 \%$ ), feldspar (up to $3 \%$ ), and up to $20 \%$ swell-capable clay minerals (Schneider, 1999) with their ability to adsorb released potassium, one would expect much higher emission values. For example, soils composed of loamy textured till with silty to clayey cover layers in west-central Canada exhibit K levels of 1.3 to $1.6 \%$ (Kiss et al., 1988), or Australian soils on shale bed rock exhibit $\mathrm{K}$ concentrations in the range of 0.7 to $3.0 \%$ (Dickson and Scott, 1997). 


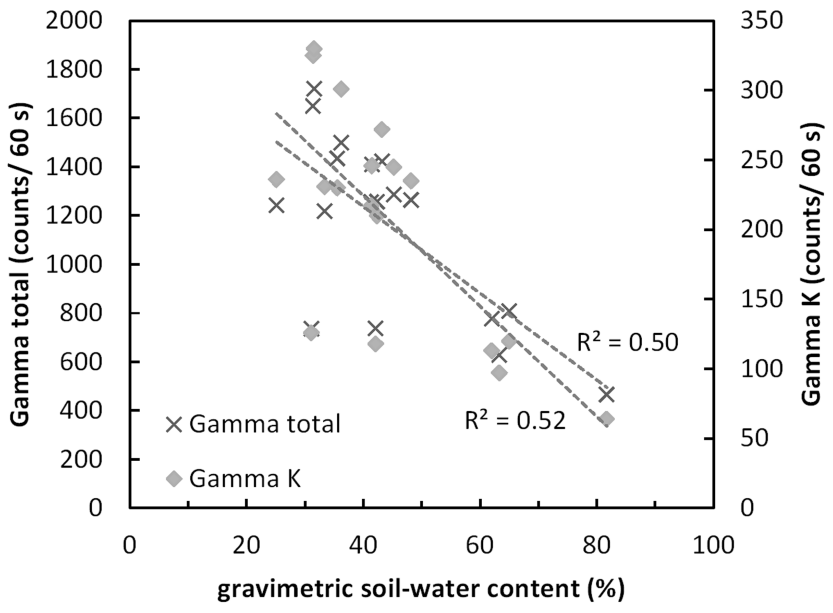

Fig. 5. Scatterplot of gravimetric soil-water content and total gamma counts (left axis) and radioaktive $\mathrm{K}$ (right axis).

At the Heumöser, the relatively low radioactive emissions are regarded as consequence the of special soil conditions. Soil textures and soil-water contents are mutually dependent from each other, e.g., organic or peaty soils can adsorb much more water than mineral soils. Soil moisture in turn increases the bulk density of soils and, thus, the attenuation of gamma radiation, approximately by $1 \%$ for each increment of $1 \%$ volumetric water content (Cook et al., 1996). Lowest gamma-ray emission was, thus, found in places with high soil-water contents. When cross-plotting all obtained gravimetric water contents and gamma-ray data, a notably negative correlation becomes evident with Total Count and $\mathrm{K}$ radioactivity measurements (Fig. 5). The higher the soilwater content, the lower the gamma-ray emission. This attenuation effect of gamma-ray fluxes, in particular from $\mathrm{K}$ and Th with increasing soil moisture, is known from results achieved by airborne gamma-ray measurements and utilised for quantifying soil-water contents based on repeatedly measured gamma-ray emission (e.g., Carroll, 1981; Grasty, 1997). Similar attenuation effect could be assumed for results obtained from the Heumöser based on the relationship in Fig. 5. However, quantification is not possible by means of the snap shot, and qualitative assessment remains arguable to a certain extent without detailed soil analyses. However, taken field descriptions of collected samples into account, a direct proportionality between gamma-ray flux and soil moisture and related soil texture becomes evident. The four samples with high water contents larger than $60 \%$ are organic-rich soils from the eastern part of the slope. The other samples with varying water contents and similar and higher gamma emissions originate from rather mineral soils randomly distributed over the study site. Even though uncertainties remain, spatially obtained gamma data allows for a first assessment of soil conditions with emphasis on relative water contents of the topsoil based on the correlation shown in Fig. 5.
Table 2. Results of the PCA: the Component Loadings shows the variance of each variable explained by three factors. Maximum variances of the selected variables for cluster analysis are explained by different factors (italic). Below the respective percentage of the three factors which explain altogether $92 \%$ of total variance.

\begin{tabular}{lrrr}
\hline Component loadings & \multicolumn{1}{c}{1} & \multicolumn{1}{c}{2} & \multicolumn{1}{c}{3} \\
\hline EC_h May & 0.358 & 0.412 & -0.833 \\
EC_v May & -0.692 & 0.484 & -0.101 \\
EC_h June & -0.016 & 0.935 & 0.153 \\
EC_v June & -0.588 & 0.740 & 0.244 \\
Total Count & 0.976 & 0.162 & 0.087 \\
Gamma K & 0.969 & 0.148 & 0.084 \\
Gamma U & 0.916 & 0.214 & 0.136 \\
Gamma Th & 0.955 & 0.147 & 0.087 \\
\hline Total variance & 57.44 & 24.26 & 10.35 \\
explained [\%] & & & \\
\hline
\end{tabular}

\subsection{Hill-slope characterisation and partitioning}

The ambiguous relationship between electrical conductivity and gamma-ray flux and the highly heterogeneous soil properties at the Heumöser hamper the straightforward characterisation of subsurface structures or soil state variables by means of EMI or gamma-ray spectroscopy. Therefore, we use selected variables from both methods for a joint analysis based on a cluster algorithm in order to identify zones of similar soil conditions. The so-called zonal approach (based on e.g., $k$ means or fuzzy $c$ means clustering) has become a common tool in geophysical data analysis for delineating subsurface structures and estimating petrophysical parameters (e.g., Tronicke et al., 2004; Dietrich and Tronicke, 2009; Paasche et al., 2010; Altdorff and Dietrich, 2012). We chose $k$ means clustering because of its simple performance and robust results, using the software Systat. Input variables were EC h data from both May and June surveys, as well as Total Count gamma-ray data, because these variables provide independent information from a similar shallow exploration depth. Independency was tested by means of principle component analysis (PCA), in which all variables were included. Results of PCA are shown in Table 2. For the $k$ means cluster algorithm, Mahalanobis distance was used as a metric for the measuring distance of data, as it takes the different scales of input variables into account. Cluster analysis was applied on re-gridded data with a $5 \mathrm{~m}$ raster that were generated from the kriging interpolation maps shown in Figs. 2 and 4.

A critical issue when utilising the zonal approach is the choice of optimum number of clusters, which is usually specified by a priori information, data analysis using, e.g., cross plots, or statistical criteria. Variance ratio criterion, originally introduced by Calinski and Harabasz (1974), is a widely used criterion, which uses the quotient between the intra-cluster average squared distance and inter-cluster average squared 
distance. The optimal solution of this criterion is the number of clusters that maximises the value of the variance criterion.

Based on the statistical criterion, a 2 cluster and a 5 cluster model would be appropriate results according to the input variables (Fig. 6). Zonation into only two subareas (a steeper northwest, and an eastern part), however, is not a meaningful partitioning of the hill-slope surface with regards to the spatially high-resolution geophysical measurements, as well as to further a priori information. We rely on additional information from an ecological moisture index that has been obtained from mapping indicator vegetation and soil cores from the entire catchment (Lindenmaier et al., 2005). This available ecological moisture map discriminates between five different classes of soil conditions, thus, the 5 cluster solution appears to be an adequate zonation model for the hill-slope area. A detailed map of the classified patches of ecological plant moisture that matches the extent of geophysical mapping, as well as the partitioning of the hill-slope area according to the 5 cluster model, is shown in Fig. 7.

Both maps in Fig. 7 show a comparable pattern of hillslope partitioning into zones of similar subsurface conditions. Based on ecological classification, the study area is characterised by very moist to very wet soil conditions with stagnic properties in plane areas, and some drier bulging areas in the steeper northwest (Lindenmaier et al., 2005). Similar conditions can be assumed for the obtained cluster partitioning, even though a detailed assessment of the qualities of the clusters is complicated by the ambiguous relationship between the measured physical parameters and the soil properties. However, at least the cluster numbers 1 and 5 can be regarded as being relatively well defined, in accordance with the characteristics of allocated data shown in Fig. 8. Thus, according to the low gamma values and their specific relation to soil-water content, cluster 1 is very likely to specify wet soil conditions analog to the dark grey area of the ecological moisture map, which is independently confirmed by the high water contents of the soil samples concerned (Fig. 8b). Secondly, cluster 5 matches the extent of the area categorised as an artificial surface in Fig. 8a, which is in accordance with the highest gamma values interpreted as artificial backfill material. All further clusters were statistically defined, showing only little differences in individual characteristics (Fig. 8). However, this statistical result is close to real environmental conditions because natural soils in this hill-slope area belongs mainly to HRU 2 according to Lindenmaier et al. (2005), a region with highly variable relief with smallscale features like bulging and plane areas. Soils are generally moist to wet due to stagnic properties of the subsurface. Independent of small-scale feature of relief, soil conditions may vary erratically. Different methodologies, e.g., botanical or geophysical approaches, detect this variability according to their sensitivity.

Basically, when comparing and examining both maps of hill-slope donation, one should keep in mind the very different approaches and data used for cluster partitioning.

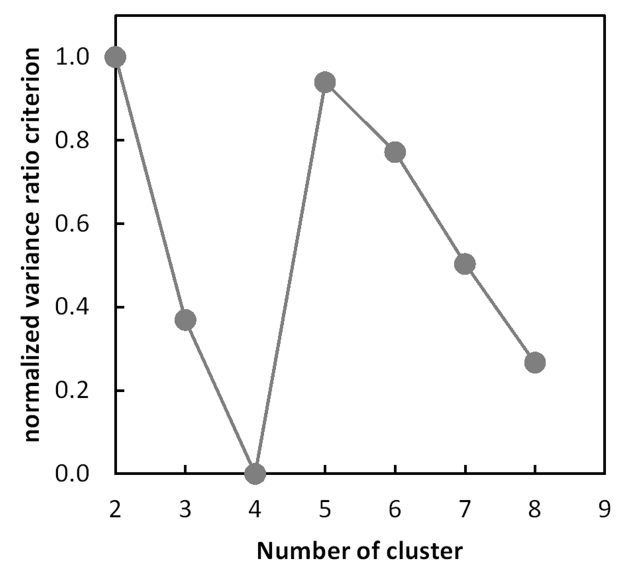

Fig. 6. Normalised variance ratio criterion as a function of the optimum number of clusters.

Ecological mapping is based on the tolerance range of plants to the availability of moisture and qualitative and quantitative soil properties (e.g., soil type, layer depth, organic content and colour). Given an undisturbed surface and natural vegetation, these properties describe long-term characteristics of a habitat. In contrast, geophysical methods provide a snap shot of the spatial variability of specific proxy values (physical variables) at the moment of surveying. However, since soil-moisture conditions are described as relatively stable through the year, with only $10 \%$ seasonal variability in the topsoil (Lindenmaier et al., 2005), results of geophysical exploration provide information on general subsurface characteristics of the Heumöser, independently from vegetation period. Regardless of the different procedures, a comparable partition of the shallow hill-slope subsurface with geophysical surveying has been achieved, and demonstrated the potential for rapid surveying and assessment of soil conditions of heterogeneous and complex field sites at the intermediate landscape scale.

\section{Conclusions}

The combination of EMI and gamma-ray spectroscopy has proven to be a suitable approach for mapping soil proxy values rapidly at the intermediate hill-slope scale. Both survey designs "on-the-go" and point measurements provided appropriate datasets for analysing spatial variability and identifying subsurface structures by means of kriging interpolation. A quantification of soil qualities, in particular soil moisture based on the proxy values was not possible due to ambiguous relationship of electrical conductivity and gammaray flux to the highly heterogeneous soil conditions. Based on few soil-sample analyses, no relevant relationship was found to exist between soil moisture and ECa for the entire test site. Gamma-ray emissions seemed to be negatively correlated with soil-water content. It is an open question for further field 


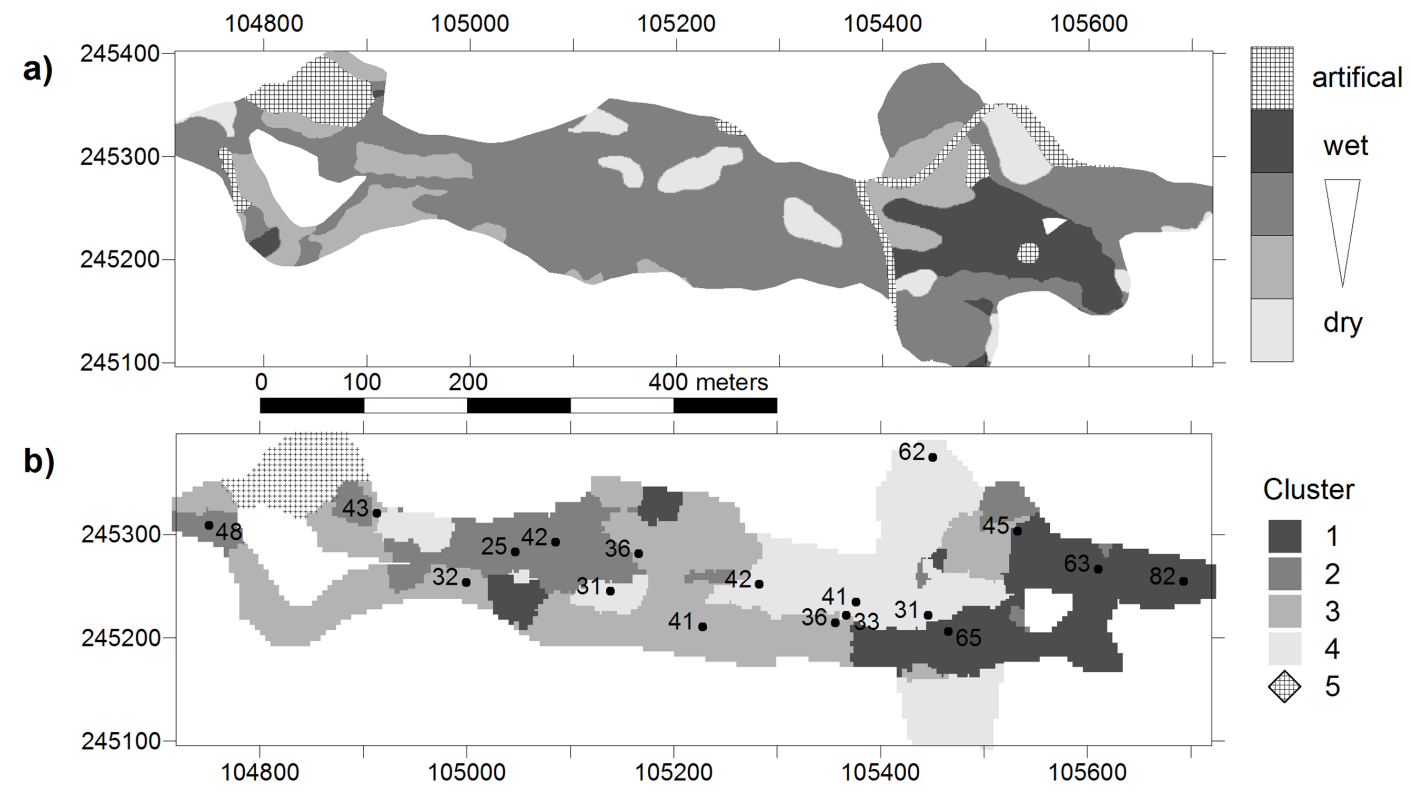

Fig. 7. Detail map of hill-slope partitioning based on (a) the ecological zonation according to Lindenmaier et al. (2005), and (b) the 5-cluster model with locations of the soil samples. The numbers denote the determined soil-water contents. The different shades of grey in both maps indicate the different ecological classes and clusters, respectively. Coordinates on $\mathrm{x}$ - and y-axis are in metric BMN M28 Austrian coordinate system.

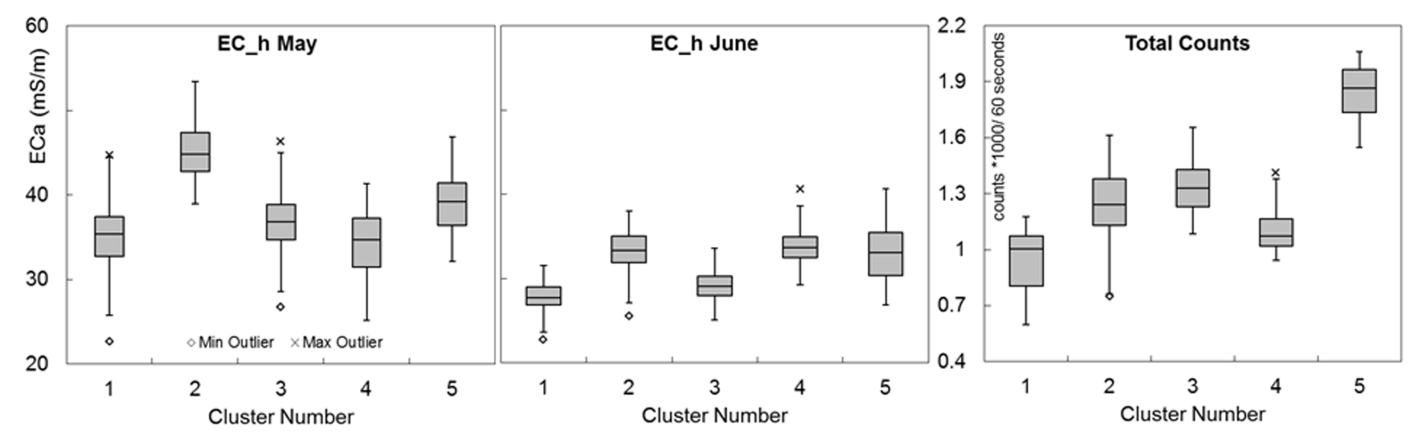

Fig. 8. Characteristics of input variables in the respective clusters. The top and bottom of the boxes indicate the upper and lower quartile, the line inside refers to the median value. Whiskers define the data range within the $1.5 \mathrm{IQR}$ (interquartile range), and values off the IQR are given as outliers. Note the different scales of the y-axis between ECa and gamma data plots.

tests, if more samples or more detailed laboratory analyses, e.g., particle size analysis, would establish more reliable and significant relationships between the recorded proxy values and soil state variables.

However, despite the uncertainties of the applied methods, we obtained valuable information on soil conditions by qualitative analyses of the proxy values. Based on EMI measurements, we revealed the relative variability of ECa from two different depth intervals that showed an increased spatial and vertical heterogeneity of distinct soil conditions in May, compared to more smoothed ECa pattern in June. For a detailed assessment, changes in soil moisture based on repeated soil sampling should be included into further monitoring activities. Emission data obtained from a single gamma-ray survey seemed to be closer related to soil-moisture, as shown by the notable correlation between Total Count and $\mathrm{K}$ results with gravimetric water contents. Besides a relative monitoring, it appears possible to implement a semi-quantification of soil-water contents based on repeated gamma-ray measurements together with few samples for obtaining water contents of clayey soils. Finally, the results of both EMI and gammaray methods enabled a meaningful partitioning of hill-slope subsurface into zones of similar subsurface conditions that was in exceptionally good agreement with the previously obtained hill-slope partitioning based on ecological factors. Therefore, we believe that qualitative, but area-wide information on soil conditions based on proxy values are very useful for a primary exploration of larger study areas prior to more detailed investigations in terms of implementing a 
hierarchical site investigation approach for future targeted measures in relevant subareas.

Acknowledgements. The authors thank Malte Ibs-von Seht (Federal Institute for Geosciences and Natural Resources, BGR, Germany) for providing the gamma-ray spectrometer and David Sauer (University of Potsdam, Germany) for his assistance during fieldwork. This work was funded by Deutsche Forschungsgemeinschaft as part of the research unit "Coupling of flow and Deformation processes for modelling the movement of natural slopes (DFG research unit 581).

The service charges for this open access publication have been covered by a Research Centre of the Helmholtz Association.

Edited by: L. Pfister

\section{References}

Altdorff, D. and Dietrich, P.: Combination of electromagnetic induction (EMI) and gamma-spectrometry using $k$-means clustering: A study for evaluation of site partitioning, J. Plant Nutr. Soil Sci., 175, 345-354, 2012.

Brevik, E. C., Fenton, T. E., and Lazari, A.: Soil electrical conductivity as a function of soil water content and implications for soil mapping, Precision Agr., 7, 393-404, 2006.

Calinski, T. and Harabasz, J.: A dendrite method for cluster analysis, Commun. Stat., 3, 1-27, 1974.

Callegary, J. B., Ferré, T. P. A., and Groom, R. W.: ThreeDimensional Sensitivity Distribution and Sample Volume of Low-Induction-Number Electromagnetic-Induction Instruments, Soil Sci. Soc. Am. J., 76, 85-91, 2012.

Carroll, T. R: Airborne soil moisture measurements using natural terrestrial gamma radiation, Soil Sci., 132, 358-366, 1981.

Carroll, Z. L. and Oliver, M. A.: Exploring the spatial relations between soil physical properties and apparent electrical conductivity, Geoderma, 128, 354-374, 2005.

Chambers, J. E., Wilkinson, P. B., Kuras, O., Ford, J. R., Gunn, D. A., Meldrum, P. I., Pennington, C. V. L., Weller, A. L., Hobbs, P. R. N., and Ogilvy, R. D.: Three-dimensional geophysical anatomy of an active landslide in Lias Group mudrocks, Cleveland Basin, UK, Geomorphology, 125, 472-484, 2011.

Cockx, L., Van Meirvenne, M., and De Vos, B.: Using the EM38DD Soil sensor to delineate clay lenses in a sandy forest soil, Soil Sci. Soc. Am. J., 71, 1314-1322, 2007.

Cook, S. E., Corner, R. J., Groves, P. R., and Grealish, G. J.: Use of airborne radiometric data for soil mapping, Aust. J. Soil Res., 34, 183-194, 1996.

Corwin, D. L. and Lesch, S. M.: Application of Soil Electrical Conductivity to Precision Agriculture: Theory, Principles, and Guidelines, Agron. J., 95, 455-471, 2003.

Corwin, D. L., Kaffka, S. R., Hopmans, J. W., Mori, Y., van Groenigen, J. W., van Kessel, C., Lesch, S. M., and Oster, J. D.: Assessment and field-scale mapping of soil quality properties of a saline sodic soil, Geoderma, 114, 231-259, 2003.
Depenthal, C. and Schmitt, G.: Monitoring of a landslide in Vorarlberg/ Austria, in: 11th Proc. Int. FIG Symp. on Deformation Measurements, Santorini (Thera) Island, Greece, edited by: Stiros, S. and Pytharouli, S., 289-295, 2003.

Dickson, B. L. and Scott, K. M.: Interpretation of aerial gamma ray surveys-adding the geochemical factors, AGSO J. Aust. Geol. Geophys., 17, 187-200, 1997.

Dietrich, P. and Tronicke, J.: Integrated analysis and interpretation of cross-hole P- and S-wave tomograms: a case study, Near Surf. Geophys., 7, 101-109, 2009.

Domsch, H. and Giebel, A.: Estimation of soil textural features from soil electrical conductivity recorded using the EM38, Precision Agr., 5, 389-409, 2004.

Ewing, R. P. and Hunt, A. G.: Dependence of the Electrical Conductivity on Saturation in Real Porous Media, Vadose Zone J., 5, 731-741, 2006.

Grasty, R. L.: Radon emanation and soil moisture effects on airborne gamma-ray measurements, Geophysics, 62, 1379-1385, 1997.

Kinal, J., Stoneman, G. L., and Williams, M. R.: Calibrating and using an EM31 electromagnetic induction meter to estimate and map soil salinity in the jarrah and karri forests of south-western Australia, Forest Ecol. Manage., 233, 78-84, 2006.

Kiss, J. J., De Jong, E., and Bettany, J. R.: The distribution of natural radionuclides in native soils of southern Saskatchewan, Canada, J. Environ. Qual., 17, 437-445, 1988.

Lindenmaier, F., Zehe, E., Dittfurth, A., and Ihringer, J.: Process identification at a slow-moving landslide in the Vorarlberg Alps, Hydrol. Process., 19, 1635-1651, 2005.

Martínez, G., Vanderlinden, K., Giráldez, J. V. Espejo, A. J., and Muriel, J. L.: Field-Scale Soil Moisture Pattern Mapping using Electromagnetic Induction, Vadose Zone J., 9, 871-881, 2010.

McNeill, J. D.: Electrical conductivity of soils and rocks, Technical Note TN-5, Geonics Ltd. Mississauga, Ontario, p. 22, 1980a.

McNeill, J. D.: Electromagnetic terrain conductivity measurement at low induction numbers, Technical Note TN-6, Geonics Ltd. Mississauga, Ontario, p. 15, 1980 b.

Minty, B.: Fundamentals of airborne gamma-ray spectrometry, AGSO J. Aust. Geol. Geophys., 17, 39-50, 1997.

Paasche, H., Tronicke, J., and Dietrich, P.: Automated integration of partially collocated models: Subsurface zonation using a modified fuzzy c-means cluster analysis algorithm, Geophysics, 75, P11-P22, 2010.

Pracilio, G., Adams, M. L., Smettem, K. R. J., and Harper, R. J.: Determination of spatial distribution patterns of clay and plant available potassium contents in surface soils at the farm scale using high resolution gamma ray spectrometry, Plant Soil, 282, 67-82, 2006.

Reedy, R. C. and Scanlon, B. R.: Soil Water Content Monitoring Using Electromagnetic Induction, J. Geotech. Geoenviron. Eng., 129, 1028-1039, 2003.

Robinson, D. A., Lebron, I., Kocar, B., Phan, K., Sampson, M., Crook, N., and Fendorf, S.: Time-lapse geophysical imaging of soil moisture dynamics in tropical deltaic soils: An aid to interpreting hydrological and geochemical processes, Water Resour. Res., 45, W00D32, doi:10.1029/2008WR006984, 2009. 
Robinson, D. A., Abdu, H., Lebron, I., and Jones, S. B.: Imaging of hill-slope soil moisture wetting patterns in a semi-arid oak savanna catchment using time-lapse electromagnetic induction, J. Hydrol., 416-417, 39-49, 2012.

Sass, O., Bell, R., and Glade, T.: Comparison of GPR, 2D-resistivity and traditional techniques for the subsurface exploration of the Oschingen landslide, Swabian Alb (Germany), Geomorphology, 93, 89-103, 2008.

Schneider, U.: Untersuchungen zur Kinematik von Massenbewegungen im Modellgebiet Ebnit (Vorarlberger Helvetikum), Diss. Univ. Karlsruhe, Karlsruhe, Germany, 1999.

Schrott, L. and Sass, O.: Application of field geophysics in geomorphology: Advances and limitations exemplified by case studies, Geomorphology, 93, 55-73, 2008.

Sheets, K. R. and Hendrickx, J. M. H.: Noninvasive soil water content measurement using electromagnetic induction, Water Resour. Res., 31, 2401-2409, 1995.

Taylor, M. J., Smettem, K., Pracilio, G., and Verboom, W.: Relationships between soil properties and high-resolution radiometrics, central eastern Wheatbelt, Western Australia, Explor. Geophys., 33, 95-102, 2002.

Tromp-van Meerveld, H. J. and McDonnell, J. J.: Assessment of multi-frequency electromagnetic induction for determining soil moisture patterns at the hill slope scale, J. Hydrol., 368, 56-67, 2009.
Tronicke, J., Holliger, K., Barrash, W., and Knoll, M. D.: Multivariate analysis of crosshole georadar velocity and attenuation tomograms for aquifer zonation, Water Resour. Res., 40, W01519, doi:10.1029/2003WR002031, 2004.

Van Dam, R. L.: Landform characterisation using geophysics - Recent advances, applications, and emerging tools, Geomorphology, 137, 57-73, 2012.

Viscarra Rossel, R. A., Taylor, H. J., and McBratney, A. B.: Multivariate calibration of hyperspectral $\gamma$-ray energy spectra for proximal soil sensing, Eur. J. Soil Sci., 58, 343-353, 2007.

Wienhöfer, J., Lindenmaier, F., and Zehe, E.: Challenges in Understanding the Hydrologic Controls on the Mobility of SlowMoving Landslides, Vadose Zone J., 10, 496-511, 2011.

Wilford, J. R., Bierwirth, P. N., and Craig, M. A.: Application of airborne gamma-ray spectrometry in soil/regolith mapping and applied geomorphology, AGSO J. Aust. Geol. Geophys., 17, 201216, 1997.

Zhu, Q., Lin, H., and Doolittle, J.: Repeated Electromagnetic Induction Surveys for Improved Soil Mapping in an Agricultural Landscape, Soil Sci. Soc. Am. J., 74, 1763-1774, 2010a.

Zhu, Q., Lin, H., and Doolittle, J.: Repeated Electromagnetic Induction Surveys for Determining Subsurface Hydrologic Dynamics in an Agricultural Landscape, Soil Sci. Soc. Am. J., 74, 1750$1762,2010 b$. 